\title{
EFEITOS DA AUTOCLAVAÇÃO NA VELOCIDADE E CAPACIDADE ABSORVENTE DE CONES DE PAPEL EMPREGADOS EM ENDODONTIA
}

\author{
AUTOCLAVING EFFECT ON THE ABSORPTION VELOCITY AND \\ CAPABILITY OF PAPER POINTS USED IN ENDODONTICS
}

\author{
Claudio Hideki KUBO* \\ Ana Paula Martins GOMES** \\ Antonio Olavo Cardoso JORGE***
}

\begin{abstract}
KUBO, C. H.; GOMES, A. P. M.; JORGE, A. O. C. Efeitos da autoclavação na velocidade e capacidade absorvente de cones de papel empregados em Endodontia. Rev Odontol Univ São Paulo, v. 13, n. 4, p. 383-389, out./dez. 1999.
\end{abstract}

\begin{abstract}
A presença de umidade no interior do sistema de canais radiculares, após o preparo biomecânico e sua desinfecção, pode influenciar no selamento apical e no êxito da obturação endodôntica. O objetivo deste trabalho foi avaliar a influência do número de esterilizações em autoclave, sobre a capacidade e velocidade de absorção dos cones de papel empregados em Endodontia. Foram analisados 440 cones de papel número 40, dos quais dez cones de cada marca comercial receberam de zero à dez ciclos de esterilização em autoclave $\left(134^{\circ} \mathrm{C} / 15 \mathrm{psi} / 15\right.$ minutos $)$. Após cada ciclo de esterilização, os cones foram avaliados quanto a capacidade e velocidade de absorção de solução de hipoclorito de sódio a $1 \%$. Os dados foram submetidos à análise estatística por meio dos testes da ANOVA (dois critérios) e Tukey (5\%). Pôde-se concluir que, quanto à capacidade de absorção, os cones que sofreram menor influência dos diversos ciclos de esterilização em autoclave foram, em ordem decrescente: Tanari, Tanari "cell pack", Conne e Diadent "cell pack". Quanto à velocidade de absorção, os cones que obtiveram os melhores resultados foram: Tanari "cell pack", Tanari, Conne e Diadent "cell pack". A autoclavação mostrou-se um procedimento viável, em até 10 ciclos, apenas para a esterilização de cones de papel absorvente da marca Tanari utilizados em Endodontia.
\end{abstract}

UNITERMOS: Esterilização; Endodontia.

\section{INTRODUÇÃO}

A presença de umidade no interior do sistema de canais radiculares, após o preparo biomecânico e sua desinfecção, é um dos fatores que podem influenciar no selamento marginal da obturação endodôntica, e, conseqüentemente, no êxito do tratamento endodôntico ${ }^{3,6,7,8}$. Diversos métodos para secagem do sistema de canais radiculares têm sido empregados, tais como: álcool ${ }^{13,24}$; mechas de algodão ${ }^{22}$; cones de papel absorvente ${ }^{2,17,19}$ e cânulas de aspiração em associação a cones de papel absorvente $^{6,7,8,20}$.

Atualmente, os cones de papel absorvente, constituem-se no método mais utilizado para a secagem do sistema de canais radiculares ${ }^{20}$, determi- nação da cor e qualidade do exsudato dentro do canal $^{3}$, tomada de amostras para cultivo microbiológico e na colocação de curativo de demora em Endodontia ${ }^{5,12,17,19}$, devendo portanto estar e permanecer esterilizados até o seu uso. Porém no Brasil, os cones de papel são usualmente comercializados em caixas contendo aproximadamente 200 unidades, em tamanhos estandardizados e esterilizados. Contudo, durante a remoção dos cones a serem utilizados, os demais podem ser contaminados, fazendo com que muitos profissionais recorram a novas esterilizações ${ }^{2}$. A partir do exposto, o objetivo do presente trabalho foi avaliar a influência do número de esterilizações em autoclave sobre a velocidade e capacidade de absorção dos cones de papel empregados em Endodontia.

\footnotetext{
*Estagiário; ** Professora Assistente Doutora - Disciplina de Endodontia do Departamento de Odontologia Restauradora; *** Professor Adjunto da Disciplina de Microbiologia e Imunologia do Departamento de Biopatologia e Diagnóstico do Câmpus de São José dos Campos - UNESP.
} 
KUBO, C. H.; GOMES, A. P. M.; JORGE, A. O. C. Efeitos da autoclavação na velocidade e capacidade absorvente de cones de papel empregados em Endodontia. Rev Odontol Univ São Paulo, v. 13, n. 4, p. 383-389, out./dez. 1999.

\section{MATERIAL E MÉTODOS}

Foram avaliados 440 cones de papel absorvente, de número 40 de estandardização e divididos, conforme a marca e a apresentação comercial, em: Conne (Conne Ltda); Tanari (Tanari Industrial Ltda); Tanari "cell pack" (Tanari Industrial Ltda) e Diadent "cell pack" (Diamond Dental Industrial Co. Ltd). Cada cone avaliado recebeu duas marcas, feitas com lápis preto, à distância de cinco e quinze milimetros de sua extremidade mais fina. A seguir os cones foram divididos, conforme a marca comercial, em 4 grupos, sendo cada grupo constituído de 11 subgrupos, formados de 10 cones de papel empacotados em papel kraft, que receberam, respectivamente, de zero a dez ciclos de esterilização em autoclave (Tuttnauer 2340MK) a $134^{\circ} \mathrm{C} / 15$ psi/ 15 minutos. Posteriormente, cada cone foi pesado em balança analítica (Mettler Toledo AB204), com precisão de 0,01 mg, para se verificar o peso de sua massa seca $\left(\mathrm{m}_{1}\right)$.

\section{Velocidade de absorção}

Foi determinada segundo a metodologia descrita por HOLLAND et al. ${ }^{12}$ (1988), empregando-se um dispositivo constituído de duas lâminas de vidro suspensas em colunas, e distantes 10 milímetros entre si. Em uma das lâminas de vidro, depositou-se $2 \mathrm{ml}$ de solução de hipoclorito de sódio a $1 \%$ (Pharmacia Dinâmica) e a seguir, 5 milímetros da extremidade mais fina de cada cone foram mergulhados na massa líquida e imediatamente cronometrado o tempo que o líquido demorava para percorrer o espaço de 10 milímetros demarcados (Figura 1).

\section{Capacidade de absorção}

Após a verificação do tempo de absorção de cada cone de papel, os mesmos permaneciam no dispositivo até que se observasse a sua completa umectação com a solução de hipoclorito de sódio a $1 \%$. A seguir, foi verificado o peso de sua massa

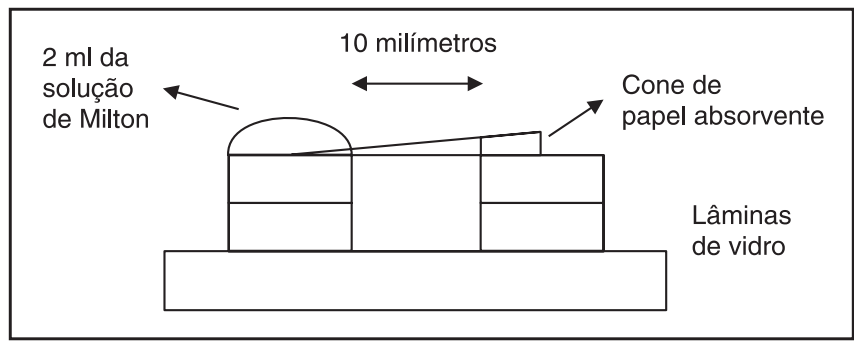

FIGURA 1 - Dispositivo empregado para verificação da velocidade de absorção. úmida $\left(\mathrm{m}_{2}\right)$ em balança analítica. A avaliação da capacidade de absorção (percentual de absorção do cone de papel estudado em relação ao próprio peso) foi calculada pela diferença entre sua massa úmida $\left(\mathrm{m}_{2}\right)$ e massa seca $\left(\mathrm{m}_{1}\right)$ dividida por sua massa seca $\left(\mathrm{m}_{1}\right)$, conforme LOPES et al. ${ }^{18}, 1992$ e SILVA et al. $^{23}, 1989$.

$$
\text { Percentual de absorção: } \frac{m_{2}-m_{1}}{m_{1}}
$$

Os resultados obtidos através dos experimentos foram submetidos à análise estatística por meio dos testes da ANOVA (dois critérios) e Tukey a nivel de significância de $5 \%$.

\section{RESULTADOS}

Nas Tabelas 1 e 2 pode-se observar a média e desvio padrão da velocidade e da capacidade de absorção dos cones estudados. Pode-se observar na Tabela 3, com relação à velocidade de absorção, que os cones da marca Tanari "cell pack" e Diadent "cell pack" não sofreram influência do número de esterilizações em autoclave. Quanto a capacidade de absorção (percentual de absorção) dos cones de papel, pode-se verificar na Tabela 4 que os cones Tanari não sofreram influência dos diversos ciclos de esterilização em autoclave, porém os cones da marca Diadent "cell pack" apresentaram diferenças estatisticamente significantes, com relação ao ciclo 0 , quando passaram a ser esterilizados por mais de duas vezes.

Na Tabela 5 observa-se que não ocorreram diferenças estatisticamente significantes entre os cones de papel da marca Conne e Tanari "cell pack", com relação à velocidade de absorção. Na Tabela 6, com relação à capacidade de absorção, pode-se observar que os cones de papel da marca Diadent "cell pack" apresentaram capacidade de absorção inferior ao Conne, para qualquer ciclo de esterilização, e que não existem diferenças estatisticamente significantes entre os cones da marca Tanari e Tanari "cell pack".

\section{DISCUSSÃO}

A manutenção da cadeia asséptica e a remoção de umidade do interior do sistema de canais radiculares podem influenciar o sucesso do tratamento endodôntico ${ }^{3,6,7,8,10,11}$.

PIMENTA et al. ${ }^{21}$ (1997), verificaram que amostras de cones de papel absorvente, comercializados como esterilizados pelos fabricantes, estavam contaminados. Vários métodos de esterilização têm 
KUBO, C. H.; GOMES, A. P. M.; JORGE, A. O. C. Efeitos da autoclavação na velocidade e capacidade absorvente de cones de papel empregados em Endodontia. Rev Odontol Univ São Paulo, v. 13, n. 4, p. 383-389, out./dez. 1999.

TABELA 1 - Médias e desvio padrão da velocidade de absorção (segundos) dos cones de papel esterilizados em autoclave.

\begin{tabular}{c|c|c|c|c}
\hline \hline \multirow{2}{*}{ Ciclos } & \multicolumn{4}{|c}{ Marca comercial } \\
\cline { 2 - 5 } & Conne $(\mathrm{n}=10)$ & Tanari $(\mathrm{n}=10)$ & Tanari “cell pack" $(\mathrm{n}=10)$ & Diadent “cell pack" $(\mathrm{n}=10)$ \\
\hline 0 & $23,45 \pm 8,84$ & $49,02 \pm 23,08$ & $17,78 \pm 4,43$ & $26,76 \pm 8,06$ \\
\hline 1 & $15,82 \pm 9,01$ & $10,13 \pm 3,16$ & $10,50 \pm 3,21$ & $25,83 \pm 7,9$ \\
\hline 2 & $12,82 \pm 4,36$ & $14,45 \pm 3,54$ & $12,52 \pm 2,33$ & $19,83 \pm 6,53$ \\
\hline 3 & $21,25 \pm 13,66$ & $9,03 \pm 2,37$ & $11,02 \pm 2,28$ & $24,77 \pm 7,49$ \\
\hline 4 & $16,7 \pm 9,54$ & $10,40 \pm 3,38$ & $11,32 \pm 2,31$ & $21,76 \pm 7,72$ \\
\hline 5 & $13,8 \pm 6,88$ & $13,05 \pm 4,32$ & $8,35 \pm 1,72$ & $21,23 \pm 4,80$ \\
\hline 6 & $10,65 \pm 4,17$ & $11,00 \pm 2,20$ & $9,53 \pm 1,80$ & $25,81 \pm 5,35$ \\
\hline 7 & $9,86 \pm 6,84$ & $10,18 \pm 2,87$ & $13,40 \pm 2,86$ & $23,08 \pm 3,31$ \\
\hline 8 & $11,35 \pm 6,25$ & $8,33 \pm 1,50$ & $10,01 \pm 2,30$ & $17,65 \pm 4,90$ \\
\hline 9 & $13,56 \pm 7,80$ & $12,37 \pm 3,13$ & $11,99 \pm 1,65$ & $17,84 \pm 6,91$ \\
\hline 10 & $12,55 \pm 7,78$ & $12,95 \pm 3,50$ & $10,66 \pm 3,01$ & \\
\hline \hline
\end{tabular}

TABELA 2 - Médias e desvio padrão da capacidade de absorção (percentagem) em relação ao próprio peso dos cones de papel esterilizados em autoclave.

\begin{tabular}{c|c|c|c|c}
\hline \hline \multirow{2}{*}{ Ciclos } & \multicolumn{4}{|c}{ Marca comercial } \\
\cline { 2 - 5 } & Conne $(\mathrm{n}=10)$ & Tanari $(\mathrm{n}=10)$ & Tanari “cell pack" $(\mathrm{n}=10)$ & Diadent “cell pack" $(\mathrm{n}=10)$ \\
\hline 0 & $1,39 \pm 0,14$ & $0,96 \pm 0,14$ & $0,99 \pm 0,09$ & $1,09 \pm 0,09$ \\
\hline 1 & $1,16 \pm 0,20$ & $0,82 \pm 0,11$ & $0,83 \pm 0,07$ & $0,92 \pm 0,15$ \\
\hline 2 & $1,12 \pm 0,12$ & $0,91 \pm 0,19$ & $0,96 \pm 0,14$ & $0,65 \pm 0,07$ \\
\hline 3 & $1,11 \pm 0,09$ & $1,03 \pm 0,07$ & $0,88 \pm 0,09$ & $0,69 \pm 0,08$ \\
\hline 4 & $1,24 \pm 0,10$ & $1,05 \pm 0,14$ & $0,89 \pm 0,12$ & $0,70 \pm 0,06$ \\
\hline 5 & $1,16 \pm 0,10$ & $0,97 \pm 0,09$ & $0,95 \pm 0,24$ & $0,70 \pm 0,05$ \\
\hline 6 & $1,18 \pm 0,15$ & $0,96 \pm 0,09$ & $0,86 \pm 0,07$ & $0,84 \pm 0,10$ \\
\hline 7 & $1,26 \pm 0,14$ & $0,91 \pm 0,20$ & $0,74 \pm 0,11$ & $0,82 \pm 0,08$ \\
\hline 8 & $1,17 \pm 0,13$ & $0,89 \pm 0,07$ & $0,96 \pm 0,09$ & $0,56 \pm 0,09$ \\
\hline 9 & $1,18 \pm 0,14$ & $0,88 \pm 0,13$ & $0,76 \pm 0,06$ & $0,82 \pm 0,14$ \\
\hline 10 & $1,21 \pm 0,10$ & $0,93 \pm 0,10$ & $0,76 \pm 0,05$ & $0,82 \pm 0,13$ \\
\hline \hline
\end{tabular}

sido empregados para os cones de papel absorvente: calor seco $^{4,11}$, metal fundido ${ }^{14}$, esterilizador elétrico com bolinhas de vidro ${ }^{18} \mathrm{e}$ pastilhas de formaldeído ${ }^{9,10}$. Com o crescimento da preocupação com métodos eficientes de controle da infecção cruzada, tem-se difundido a utilização do autoclave, em
Odontologia, por ser um método rápido e eficiente de esterilização ${ }^{17}$.

No presente estudo utilizou-se o autoclave, a uma relação de $134^{\circ} \mathrm{C} / 15 \mathrm{psi} / 15$ minutos por ciclo de esterilização, baseado no artigo sétimo, da portaria do Centro de Vigilância Sanitária II, de 4 
KUBO, C. H.; GOMES, A. P. M.; JORGE, A. O. C. Efeitos da autoclavação na velocidade e capacidade absorvente de cones de papel empregados em Endodontia. Rev Odontol Univ São Paulo, v. 13, n. 4, p. 383-389, out./dez. 1999.

TABELA 3 - Comparação e resultados da análise estatística da velocidade de absorção, diferença nos ciclos e comparação com o ciclo zero.

\begin{tabular}{c|c|c|c|c}
\hline \hline Ciclos & Conne & Tanari & $\begin{array}{c}\text { Tanari } \\
\text { "cell pack" }\end{array}$ & $\begin{array}{c}\text { Diadent } \\
\text { "cell pack" }\end{array}$ \\
\hline 1 & $\mathrm{~ns} * *$ & $\mathrm{~s}$ & $\mathrm{~ns}$ & $\mathrm{~ns}$ \\
\hline 2 & $\mathrm{~ns}$ & $\mathrm{~s}$ & $\mathrm{~ns}$ & $\mathrm{~ns}$ \\
\hline 3 & $\mathrm{~ns}$ & $\mathrm{~s}$ & $\mathrm{~ns}$ & $\mathrm{~ns}$ \\
\hline 4 & $\mathrm{~ns}$ & $\mathrm{~s}$ & $\mathrm{~ns}$ & $\mathrm{~ns}$ \\
\hline 5 & $\mathrm{~ns}$ & $\mathrm{~s}$ & $\mathrm{~ns}$ & $\mathrm{~ns}$ \\
\hline 6 & $\mathrm{~s} *$ & $\mathrm{~s}$ & $\mathrm{~ns}$ & $\mathrm{~ns}$ \\
\hline 7 & $\mathrm{~s}$ & $\mathrm{~s}$ & $\mathrm{~ns}$ & $\mathrm{~ns}$ \\
\hline 8 & $\mathrm{~s}$ & $\mathrm{~s}$ & $\mathrm{~ns}$ & $\mathrm{~ns}$ \\
\hline 9 & $\mathrm{~ns}$ & $\mathrm{~s}$ & $\mathrm{~ns}$ & $\mathrm{~ns}$ \\
\hline 10 & $\mathrm{~ns}$ & $\mathrm{~s}$ & $\mathrm{~ns}$ & $\mathrm{~ns}$ \\
\hline \hline
\end{tabular}

* diferença estatisticamente significante;

** diferença estatisticamente não significante
TABELA 4 - Comparação e resultados da análise estatística da capacidade de absorção, diferença nos ciclos e comparação com o ciclo zero.

\begin{tabular}{c|c|c|c|c}
\hline \hline Ciclos & Conne & Tanari & $\begin{array}{c}\text { Tanari } \\
\text { "cell pack" }\end{array}$ & $\begin{array}{c}\text { Diadent } \\
\text { 'cell pack" }\end{array}$ \\
\hline 1 & $\mathrm{~s}$ & $\mathrm{~ns}$ & $\mathrm{~ns}$ & $\mathrm{~ns}$ \\
\hline 2 & $\mathrm{~s}$ & $\mathrm{~ns}$ & $\mathrm{~ns}$ & $\mathrm{~s}$ \\
\hline 3 & $\mathrm{~s}$ & $\mathrm{~ns}$ & $\mathrm{~ns}$ & $\mathrm{~s}$ \\
\hline 4 & $\mathrm{~ns}$ & $\mathrm{~ns}$ & $\mathrm{~ns}$ & $\mathrm{~s}$ \\
\hline 5 & $\mathrm{~s}$ & $\mathrm{~ns}$ & $\mathrm{~ns}$ & $\mathrm{~s}$ \\
\hline 6 & $\mathrm{~ns}$ & $\mathrm{~ns}$ & $\mathrm{~ns}$ & $\mathrm{~s}$ \\
\hline 7 & $\mathrm{~ns}$ & $\mathrm{~ns}$ & $\mathrm{~s}$ & $\mathrm{~s}$ \\
\hline 8 & $\mathrm{~s}$ & $\mathrm{~ns}$ & $\mathrm{~ns}$ & $\mathrm{~s}$ \\
\hline 9 & $\mathrm{~ns}$ & $\mathrm{~ns}$ & $\mathrm{~s}$ & $\mathrm{~s}$ \\
\hline 10 & $\mathrm{~ns}$ & $\mathrm{~ns}$ & $\mathrm{~s}$ & $\mathrm{~s}$ \\
\hline \hline
\end{tabular}

TABELA 5 - Comparação e resultados da análise estatística da velocidade de absorção, diferenças entre as marcas comerciais estudadas e comparação entre as marcas de cones estudadas no mesmo ciclo.

\begin{tabular}{|c|c|c|c|c|c|c|}
\hline \multirow{2}{*}{ Ciclos } & \multicolumn{3}{|c|}{ Conne } & \multicolumn{2}{|c|}{ Tanari } & \multirow{2}{*}{$\begin{array}{c}\text { Tanari "cell pack" } \\
\text { Diadent "cell pack" }\end{array}$} \\
\hline & Tanari & Tanari "cell pack" & Diadent "cell pack" & Tanari "cell pack" & Diadent "cell pack" & \\
\hline 0 & $\mathrm{~s}$ & ns & ns & $\mathrm{s}$ & $\mathrm{s}$ & ns \\
\hline 1 & ns & ns & ns & ns & $\mathrm{s}$ & S \\
\hline 2 & ns & ns & ns & ns & ns & ns \\
\hline 3 & $\mathrm{~s}$ & ns & ns & ns & S & S \\
\hline 4 & $\mathrm{~ns}$ & ns & ns & ns & ns & ns \\
\hline 5 & ns & ns & ns & ns & ns & ns \\
\hline 6 & ns & ns & $\mathrm{s}$ & ns & $\mathrm{S}$ & $\mathrm{s}$ \\
\hline 7 & $\mathrm{~ns}$ & ns & $\mathrm{s}$ & $\mathrm{ns}$ & $\mathrm{s}$ & $\mathrm{s}$ \\
\hline 8 & ns & $\mathrm{ns}$ & $\mathrm{s}$ & ns & $\mathrm{S}$ & $\mathrm{S}$ \\
\hline 9 & ns & ns & ns & ns & ns & $\mathrm{ns}$ \\
\hline 10 & ns & ns & ns & ns & ns & ns \\
\hline
\end{tabular}

de julho de 1995, que dispõe sobre as relações de temperatura, pressão e tempo quando se utiliza o vapor saturado sob pressão como método de esterilização. Para tanto, os resultados foram concordantes com as observações de CARVALHO ${ }^{3}$ (1990), CARVALHO et al. ${ }^{4}$ (1995) e HOLLAND et al. ${ }^{11}$
(1991), embora estes autores tenham utilizado a estufa como método de esterilização dos cones de papel absorvente, segundo os quais as sucessivas esterilizações dos cones de papel absorvente inferem alterações na propriedade de absorção. Também visualmente notou-se que os cones de papel 
KUBO, C. H.; GOMES, A. P. M.; JORGE, A. O. C. Efeitos da autoclavação na velocidade e capacidade absorvente de cones de papel empregados em Endodontia. Rev Odontol Univ São Paulo, v. 13, n. 4, p. 383-389, out./dez. 1999.

TABELA 6 - Comparação e resultados da análise estatística da capacidade de absorção, diferenças entre as marcas comerciais estudadas e comparação entre as marcas de cones estudadas no mesmo ciclo.

\begin{tabular}{|c|c|c|c|c|c|c|}
\hline \multirow{2}{*}{ Ciclos } & \multicolumn{3}{|c|}{ Conne } & \multicolumn{2}{|c|}{ Tanari } & \multirow{2}{*}{$\begin{array}{c}\text { Tanari "cell pack" } \\
\text { Diadent "cell pack" }\end{array}$} \\
\hline & Tanari & Tanari "cell pack" & Diadent "cell pack" & Tanari "cell pack" & Diadent "cell pack" & \\
\hline 0 & $\mathrm{~s}$ & $\mathrm{~s}$ & $\mathrm{~s}$ & ns & ns & ns \\
\hline 1 & s & $\mathrm{s}$ & $\mathrm{s}$ & ns & ns & ns \\
\hline 2 & $\mathrm{~s}$ & ns & $\mathrm{s}$ & ns & $\mathrm{s}$ & $\mathrm{S}$ \\
\hline 3 & ns & $\mathrm{s}$ & $\mathrm{s}$ & ns & $\mathrm{s}$ & ns \\
\hline 4 & ns & $\mathrm{S}$ & $\mathrm{S}$ & ns & $\mathrm{s}$ & $\mathrm{ns}$ \\
\hline 5 & ns & ns & $\mathrm{s}$ & ns & $\mathrm{S}$ & $\mathrm{s}$ \\
\hline 6 & $\mathrm{~s}$ & $\mathrm{~s}$ & $\mathrm{~s}$ & ns & ns & ns \\
\hline 7 & $\mathrm{~s}$ & $\mathrm{~s}$ & $\mathrm{~s}$ & ns & ns & ns \\
\hline 8 & $\mathrm{~s}$ & ns & $\mathrm{S}$ & ns & $\mathrm{S}$ & $\mathrm{S}$ \\
\hline 9 & $\mathrm{~s}$ & $\mathrm{~s}$ & $\mathrm{~s}$ & $\mathrm{~ns}$ & ns & ns \\
\hline 10 & $\mathrm{~s}$ & $\mathrm{~s}$ & $\mathrm{~s}$ & ns & ns & ns \\
\hline
\end{tabular}

adquiriram coloração amarelada e se tornavam mais rígidos à medida que os procedimentos de esterilização se sucediam, conforme verificado por CARVALHO et $a l^{4}$ (1995) e HOLLAND et al. ${ }^{11}$ (1991), que utilizaram a estufa em seu estudo.

Segundo KOPPANG et al..$^{15}$ (1989), altas temperaturas provocam alterações na coloração e na estrutura (trama das fibras) do papel, afetando a penetração de líquidos por capilaridade e possibilitando que partículas de celulose se desprendam do cone e ao alcançar os tecidos periapicais, promovam reação de corpo estranho. Por outro lado, em virtude da temperatura de esterilização em autoclave ser inferior a utilizada em estufa, mesmo após dez ciclos de esterilizações, não houve diferenças estatisticamente significantes com relação a capacidade de absorção do cone Tanari (Tabela 4), bem como do Tanari "cell pack" , com relação à velocidade de absorção (Tabela 3).

Apenas os cones de papel absorvente da marca comercial Conne apresentaram capacidade de absorção superior a 100\% em relação ao seu próprio peso independentemente do número de esterilizações (Tabela 2), resultados semelhantes aos obtidos por SILVA et al. ${ }^{23}$ (1989). Os cones de papel da marca Tanari obtiveram melhores resultados com relação à velocidade de absorção após sofrerem as esterilizações sucessivas, resultados que foram es- tatisticamente significantes (Tabela 3), sem que ocorresse também perda significativa de sua capacidade (percentual) de absorção (Tabela 4).

Os cones de papel da marca Tanari "cell pack" sofreram perda estatisticamente significante (Tabelas 2 e 4) da capacidade de absorção após o sétimo ciclo de esterilização, sugerindo que os mesmos devam ser esterilizados no máximo por seis vezes em autoclave para que não ocorra perda de sua capacidade (percentual) de absorção.

Neste estudo, não foi observada relação de proporcionalidade direta entre velocidade de absorção e massa de líquido absorvida. Resultados semelhantes foram obtidos por LOPES et al. ${ }^{18}$ (1992). É necessário ressaltar que, além das marcas comerciais estudadas, a velocidade e capacidade de absorção dos cones de papel podem ser influenciadas pela tensão superficial da solução a ser absorvida $^{1,12,16,20}$, natureza da matéria-prima empregada, solubilidade do papel e da cola, processo e lote de fabricação dos cones ${ }^{12,18}$.

\section{CONCLUSÕES}

Baseados nos resultados obtidos, podemos concluir que:

1. os cones se comportaram, quanto à velocidade de absorção, na seguinte ordem decrescente de efetividade: Tanari "cell pack", Tanari, Conne e Diadent "cell pack"; 
KUBO, C. H.; GOMES, A. P. M.; JORGE, A. O. C. Efeitos da autoclavação na velocidade e capacidade absorvente de cones de papel empregados em Endodontia. Rev Odontol Univ São Paulo, v. 13, n. 4, p. 383-389, out./dez. 1999.

2. os cones se comportaram, quanto à capacidade de absorção, na seguinte ordem decrescente de efetividade: Conne, Tanari, Tanari "cell pack" e Diadent "cell pack";

3. quanto o efeito das esterilizações sucessivas, em autoclave, os cones mantiveram a estabilidade ou sofreram influência positiva (aumentaram a velocidade e a capacidade de absorção) dos dados, na seguinte ordem decrescente: Tanari, Tanari "cell pack", Conne e

\section{Diadent "cell pack";}

4. a autoclavação mostrou-se um procedimento viável, em até 10 ciclos, apenas para a esterilização de cones de papel absorvente da marca Tanari, utilizados em Endodontia.

\section{AGRADECIMENTO}

Ao Professor Ivan Balducci pela realização da análise estatística dos resultados deste trabalho.

KUBO, C. H.; GOMES, A. P. M.; JORGE, A. O. C. Autoclaving effect on the absorption velocity and capability of paper points used in endodontics. Rev Odontol USP, v. 13, n. 4, p. 383-389, out./dez. 1999.

\begin{abstract}
The presence of humidity inside the root canal system after instrumentation and removal of the septic content can influence the apex sealing, and consequently, the success of the endodontic treatment. The goal of this paper was to evaluate the influence of the number of autoclave sterilization cycles on the absorbing capability and speed of absorption of paper points used in endodontic procedures. Four hundred and forty paper points number 40 were analyzed and the trade marks used were: Tanari, Tanari "cell pack", Diadent "cell pack" and Conne. Ten points of each manufacturer received 0 to ten cycles of autoclave sterilization $\left(134^{\circ} \mathrm{C} / 15 \mathrm{psi} / 15 \mathrm{~min}\right)$. After each sterilization cycle, absorption capability and absorption velocity to $1 \%$ sodium hypochlorite solution were evaluated. Data were analyzed statistically by the ANOVA and Tukey tests. In conclusion, the trade marks which suffered less influence by the sterilization cycles in decreasing order were: Tanari, Tanari "cell pack", Conne and Diadent. The best absorption velocities were observed in: Tanari "cell pack", Tanari, Conne and Diadent. The autoclave process seems to be a viable procedure, when 10 cycles are applied, only for the paper points of trade mark Tanari used in endodontic procedures.
\end{abstract}

UNITERMS: Sterilization; Endodontics.

\section{REFERÊNCIAS BIBLIOGRÁFICAS}

1. AlBergaria, S.; ALVES, G. Contribuição ao estudo do poder de absorção dos cones de papel absorvente. Rev Fac Odontol Univ Fed Bahia, v. 10-11, p. 19-26, 1991.

2. CALlAHAN, J. R. Sulfuric acid for opening root-canals. Dent Cosmos, v. 36, n. 12, p. 957-959, 1894.

3. CARVALHO, M. G. P. Avaliação in vitro da propriedade hidrófila das pontas absorventes sob o efeito da esterilização em estufa a seco. Pelotas, 1990. 66 p. Dissertação (Mestrado em Odontologia) - Faculdade de Odontologia, Universidade Federal de Pelotas.

4. CARVALHO, M. G. P.; DUARTE, G. C. P.; AMARAL, M. M.; MILANO, N. F. Poder de absorção das pontas de papel: influência da esterilização em estufa a seco. Avaliação "in vitro". RGO (Porto Alegre), v. 43, n. 3, p. 171-174, 1995.

5. EDWARDS, R. O.; BANDYOPADHYAY, S. Physical and mechanical properties of endodontic absorbent paper points. J Endod, v. 7, n. 3, p. 123-127, 1981.

6. HABITANTE, S. M. Análise in vitro da infiltração marginal apical do corante azul de metileno, quando da obturação do canal radicular diante da variação dos métodos de secagem. São Paulo, 1996. 62 p. Tese (Doutorado em Odontologia) - Faculdade de
Odontologia, Universidade de São Paulo.

7. HABITANTE, S. M. Estudo comparativo in vitro da secagem do canal radicular de dentes humanos, variando-se o diâmetro das cânulas, o tempo de aspiração e associando-se ou não ao uso de cones de papel absorvente. São Paulo, 1994. 91 p. Dissertação (Mestrado em Odontologia) - Faculdade de Odontologia, Universidade de São Paulo.

8. HABITANTE, S. M.; BOMBANA, A. C.; ANTONIAZZI, J. H. Estudo comparativo in vitro da secagem do canal radicular de dentes humanos, variando-se o diâmetro das cânulas, o tempo de aspiração e associando-se ou não ao uso de cones de papel absorvente. Rev ABO Nac, v. 3, n. 1, p. 50-55, fev./mar. 1995.

9. HOLLAND, R.; BERNABE, P. F. E.; GONÇALVES, J. C.; GONÇALVES, A. P.; ODA, L. S. Resposta do coto pulpar e tecidos periapicais de dentes de cães a cones de papel esterilizados em estufa ou vapores de formaldeído. Rev Bras Odontol, v. 48, n. 5, p. 2-8, 1991.

10. HOLLAND, R.; BERNABÉ, P. F. E.; NAGATA, M. J. H.; MITSUDA, S. T. Métodos de esterilização dos cones na endodontia - influência do método de esterilização dos cones de papel e de guta-percha no comportamento do tecido conjuntivo subcutâneo do rato. RGo (Porto Alegre), v. 38, n. 2, p. 133-137, 1990. 
KUBO, C. H.; GOMES, A. P. M.; JORGE, A. O. C. Efeitos da autoclavação na velocidade e capacidade absorvente de cones de papel empregados em Endodontia. Rev Odontol Univ São Paulo, v. 13, n. 4, p. 383-389, out./dez. 1999.

11. HOLLAND, R.; NERY, M. J.; SOUZA, V.; MELLO, W.; BERNABÉ, P. F. E.; FILHO, J. A. O. Efeito da esterilização em estufa no poder de absorção dos cones de papel. Odontol Mod, v. 18, n. 2, p. 6-8, mar./abr. 1991.

12. HOLLAND, R.; NERY, M. J.; SOUZA, V.; MELLO, W.; BERNABÉ, P. F. E.; FILHO, J. A. O.; SALIBA, O. Cones de papel em endodontia - velocidade de absorção de alguns tipos de cones de papel empregados em endodontia. RGO (Porto Alegre), v. 36, p. 406-408, 1988.

13. HOLLAND, R.; JUNIOR, M. Z.; SOUZA, V.; SALIBA, O. Influência de alguns procedimentos clínicos na infiltração marginal de obturações realizadas pela técnica de condensação lateral. Rev Paul Odontol, v. 13, n. 4, p. 29-38, jul./ago. 1991.

14. JÜRGENSEN, C. A. Esterilização das pontas absorventes para o teste bacteriológico de canal radicular. Odont Univ, v. 37, p. 35-37, mar./abr. 1962.

15. KOPPANG, H. S.; KOPPANG, R.; SOLHEIM, T.; AARNES, H.; STOLEN, S. O. Cellulose fibers from endodontic paper points as an etiological factor in postendodontic periapical granulomas and cysts. J Endod, v. 15, n. 8, p. 369-372, Aug. 1989.

16. KUGA, M. C.; NETO, F. M.; BERTOLINI, J. C.; KEINE, K. C. Velocidade de absorção dos cones de papel: quando utilizados detergentes aniônicos. RGO (Porto Alegre), v. 39, n. 5, p. 373-375, set./out. 1991.

17. LEONARDO, M. R.; LEAL, J. M. Endodontia: tratamento de canais radiculares. 3. ed. São Paulo : Panamericana,
1998. 908 p.

18. LOPES, H. P.; ELIAS, C. N.; COSTA FILHO, A. S.; MOTTA, A. G.; COSTA, M. M. Avaliação da capacidade de absorção de cones de papel. Rev Bras Odontol, v. 49, n. 6, p. 48-51, nov./dez. 1992.

19. PAIVA, J. G.; ANTONIAZZI, J. H. Endodontia: bases para a prática clínica. 2. ed. São Paulo : Artes Médicas, 1988. $886 \mathrm{p}$.

20. PÉCORA, J. D.; SILVA, R. G.; VANSAN, L. P.; COSTA, W. F. Avaliação in vitro do número e do tempo de permanência de cones de papel absorvente, e a influência da aspiração final, na secagem do canal radicular. Rev Odontol Univ São Paulo, v. 2, n. 2, p. 81-85, abr./jun. 1988.

21. PIMENTA, F. C.; AlenCAR, A. H. G.; ESTRElA, C.; GOULART, C. B. Avaliação da contaminação de cones de papel absorvente. In: REUNIÃO ANUAL DA SOCIEDADE BRASILEIRA DE PESQUISAS ODONTOLÓGICAS. DIVISÃO BRASILEIRA DA IADR, 14, 1997. Resumos. São Paulo: SBPqO, 1997, p. 124.

22. PUCCI, F. M.; REIG, R. Conductos radiculares: anatomía, patología y terapía. Montevideo : A. Barreiro y Ramos, 1945. 2 v.

23. SILVA, R. G.; VANSAN, L. P.; PÉCORA, J. D.; COSTA, W. F. Capacidade de absorção dos cones de papel absorventes, de diferentes marcas. Rev Odont Univ São Paulo, v. 3, n. 2, p. 354-356, abr./jun. 1989.

24. WILCOX, L. R.; WIEMANN, A. H. Effect of a final alcohol rinse on sealer coverage of obturated root canals. $\mathbf{J}$ Endod, v. 21, n. 2, p. 256-258, May 1995. 